\title{
nature
}

29 November 2001 Volume 414 Issue no 6863

\section{The good, the bad and the ugly}

Reviews of books and other creations can be highly opinionated. Editors get used to the brickbats they receive in maintaining a balance between the rights of authors and reviewers, and between fact and interpretation.

$\mathrm{F}$ ew actresses have attracted such condemnation as did Liza Minnelli in 1972. Her portrayal of Sally Bowles in Cabaret, the film based on Christopher Isherwood's Berlin Stories, stimulated a withering response in The New Leader: “The film's irredeemable disaster is its Sally Bowles: changing her into an American was bad enough; into Liza Minnelli, catastrophe... Plain, ludicrously rather than pathetically plain is what Miss Minnelli is. That turnipy nose overhanging a forward-gaping mouth and hastily retreating chin, that bulbous cranium with eyes as big (and as inexpressive) as saucers..."

Admit it, this makes compelling reading. Anyone who has seen the film will know what he means. But analytical and insightful it isn't. What's more, any reader would have done well to ignore the review and see the film.

Was the editor wrong to publish it? Not at all. An actress's appearance can be an essential aspect of her impact and thus merits comment that in any other circumstances would be purely bitchy. Should the editor have seen the film for him/herself before publishing? Of course not. Publication does not imply endorsement of the opinion, merely that the writer has an opinion worth hearing — if only to disagree with. In publishing reviewers' opinions, rudeness may not only be tolerated but may even be encouraged on those rare occasions when it makes its point all the more effectively. And a highly opinionated style may ensure that more readers persist to the end of the review. The trick is to ensure that there is a foundation for the review - whether it be the reviewer's reputation or analytical prose - that gives it credibility.

Like actresses, books may deserve blistering dismissal. Nature doesn't pursue polemic for its own sake, but has published some highly opinionated reviews in its time, and has tended to give complaining authors short shrift - they've had their say in their

\section{Fallout from EuroWars}

Analogies with a current conflict seem apt.

ए ven the United States, with a single military command chain, inadvertently bombs Red Cross food depots. A United States of Europe for research is still off the radar screen, and collateral damage is inevitable when the interests of feuding factions prevail over coordinated strategies of mutual value. The excellent European Bioinformatics Institute came under friendly fire in 1999 when its funds dried up after member states blocked the European Commission from funding large-scale research infrastructure. Europe's commanders now risk repeating the error, hitting efforts to deepen Europe's advanced research networks (see page 475).

Support for research infrastructure has been the rallying cry of Philippe Busquin, head of research at the European Commission, with apparently whimsical support from the council of research ministers - a sort of uneasy Northern Alliance of the 15 member-state warlords of the European Union (EU) who control 95\% of European research funds. Busquin wants a research policy of European unity, but warlords believe that they manage better, and are loath to yield ground to the commission, which they suspect of power-grabbing. books, after all. Of course, a book review must be factually accurate, give some idea of what the book is about and venture an opinion on its merits and shortcomings. But it is all the better if a reviewer takes the opportunity to expand on the broader context of the book, or provide original and complementary insights into the subject matter - even if he or she is uncomplimentary along the way.

Occasionally, an editor has to step in after publication. Correcting a factual error or publishing a reviewer's retraction is relatively easy, if painful. But sometimes the matter may be less clear cut. An example is a clarification published on page 487. On this occasion, the reviewer made a strong statement about an author's characterization of a key moment in the history of science. Nature's reading of the text led to a different interpretation, and we feel it worth saying so. The reviewer can explain why, based on his reading of the text and his knowledge of the history, he interpreted the text as he did, and will do so soon. Maybe others will be encouraged to comment on the history itself, as does Alvin Weinberg on page 485.

Perhaps a more efficient approach to reviews would be to encourage extreme succinctness and unanswerably pure subjectivity, blended with an element of wit. Isherwood's Berlin Stories again stimulated a possible model — an assessment, attributed variously to Dorothy Parker or Walter Kerr, of the play by John Van Druten based on the book, entitled I Am a Camera: "Me no Leica". Or even better, a review of an exhibition of nautical watercolours: "Unseeworthy".

If we were to encourage this approach, Nature's readers would be deprived of the objectivity and rigour they value so highly, but would have more time for their own objective analyses in the lab. Editors, for sure, would avoid much strife. Alas, such elegant brevity crosses our desks all too infrequently.

The third player is the European Parliament, an assembly of tribal leaders directly elected from member states, with allegiances also to pan-European political camps. A weak body, every five years it can nonetheless veto the alliance's key strategic plank - the five-year 'Framework' programmes for joint EU research. All three parties are now engaged in trench warfare over the small print of the sixth Framework, with lines and paragraphs being taken and lost in battles that are won by horse-trading and defections.

In the heat and dust, broader perspectives are sometimes lost. Busquin's request to increase funding for infrastructure to 800 million euros (US\$700 million) risks being plundered by the other parties to pay for pet topics. Warlords prefer to divide infrastructure - and its rich pickings in jobs and prestige - among themselves. The result in the past has often been ill-coordinated development, for example in neutron and light sources. Europe's fragile coalition needs to wake up to the fact that a secure mechanism for long-term planning and support of research infrastructure, at the European level, is not an item for barter, but a fundamental priority. 